\title{
VIRTUAL ENTERPRISE ARCHITECTURE SuPPly CHAin (VEASC) MODEL ON CLOUd COMPUTING: A SIMULATION-BASED STUDY THROUGH OPNET MODELLING
}

\author{
Tlamelo Phetlhu and Sam Lubbe \\ Faculty of Commerce, Administration and Law, University of Zululand, Kwa- \\ Zulu Natal, South Africa
}

\begin{abstract}
The traditional models of electronic data interchange (EDI) and out-of-application methods for messaging and collaborations are not suitable to achieve the full benefits of VEASC because of multiple limitations. The limitations are: multiple human interventions, lack of real time visibility into the supply chain flows, inability to accurately synchronise the demand and supplyside information, and inability to build dynamic capabilities required for facing supply chain dynamics. The existing studies about deploying supply chain applications on cloud computing are focussed on overcoming these limitations through service-oriented architectures and their components. However, their focus needs to be expanded to virtual enterprise architecture modelling to overcome the limitations of EDI and out-of-application methods effectively. The virtual enterprise architecture supply chain (VEASC) model has been studied in this research employing Optimised Networking (OPNET) modelling and simulations of a commercial application called INTEND. The simulation results reflect a potential to overcome the limitations of traditional EDI and out-of-application methods. However, the true potential of the proposed system and the changes needed to automatically recover from failures can be determined after testing actual transactions in a real world VEASC implementation.
\end{abstract}

\section{KEYWORDS}

Supply chain, enterprise architecture, integration, collaboration, communications, strategic partnership, cloud computing, Optimised Networking (OPNET), modelling, simulations, simple object access protocol (SOAP), eXtensible Markup Language (XML)

\section{INTRODUCTION}

Strategic supplier management is possible on the foundations of coordination, collaboration, timely and accurate information sharing and communications between all the supplier echelons and the company managing them $[1,2,3]$. In its simplest representation, a supply chain may be viewed as a chain connecting three broad stages: raw materials acquisition, raw materials transformed into finished goods, and productions and services distribution and delivery to clients [2].

Natarajan Meghanathan et al. (Eds) : CCSEA, CLOUD, SIPRO, AIFU, SEA, DKMP, NCOM - 2019

pp. 169-186, 2019. (C) CS \& IT-CSCP 2019

DOI: $10.5121 /$ csit.2019.90914 
The value-chain model of supply chain (Figure 1) presents the bigger picture of integration, coordination, collaboration, and communications for enhancing effectiveness and efficiency of operations [1]. In the value-chain model, the supply chain may be viewed as a chain of stages between the suppliers and the customers [1,2,3]. The operations have their own cycles of processes and their underlying tasks that take inputs from the previous stage and feeding output to the next stage $[1,2,3]$. Hence, this model may also be viewed as the chain of cycles of operations $[1,2,3]$. The entire chain is supported by organisational support functions $[1,2]$. If the span of support by the support functions is extended to suppliers upstream and the customers downstream through the same system, the entire supply chain becomes a virtual enterprise [1,2]. The effectiveness of the operations of the stages is related to accuracy of their desired outcomes for meeting the customer demands, and the efficiency of the operations is related to responsiveness of the processes to the customer demands [2][4]. Hence, accuracy and responsiveness are the two fundamental targets for enhanced performance of a supply chain [2]. They are dependent upon an effective orchestration among the structural and functional units of a supply chain, achievable through the virtual enterprise model [4][5][6][7].

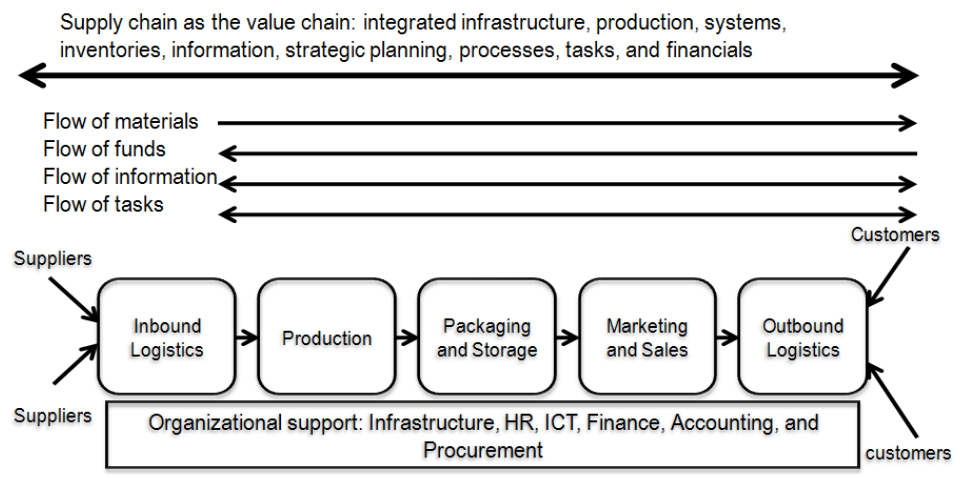

Figure 1: Value chain model of a supply chain (Source: Christopher, 2011, p. 14)

The effectiveness in orchestration of the structural and functional units of a supply chain are governed by strategic advanced planning and orientation of processes in accordance with the planning [4][8,9], strategic relationships management with the suppliers and customers [1][10,11,12], information systems and sharing framework with desired capabilities [13,14], strategic integration of the operations cycles of all the stages and their support functions (including suppliers and customers) $[15,16,17]$, and effective collaboration, cooperation, and communications among the supply chain agents working in the echelons on their respective assignments $[17,18,19]$. An example of effective orchestration of structural and function units if a supply chain is found in the strategic market networks in which, the suppliers and the production companies integrate their structural assets and function units through cross-border integration of processes, collaboration and communication channels, and information sharing [12][20]. This form of integration can integrate diverse competencies, and innovations of different organisations to form an agile, flexible, and responsive supply chain for the customers that offers enhanced value and trust to the end-customers [10][12][20,21].

Modern supply chains are heavily dependent on information and communication technologies (ICT) for not only information sharing, but also in executing collaborations, communications, coordinations, managing operations processes and their tasks [14][22]. A properly design ICT 
infrastructure with hardware, operating software, applications, workflows, and Internet integration is essential for managing and operating the virtual enterprise model [14][22]. An effective ICT infrastructure should also have ubiquitous access, platform independence, rapid and dynamic configurations, integration of multiple data sources [23,24]. The cloud computing is emerging as a platform for strategic market networking bringing together multiple suppliers and customers through an exchange facilitating exchange of funds with goods and services [24]. It is an enhanced form of the traditional electronic data interchange (EDI) and messaging and collaboration through out-of-application methods (like, e-mails and chat boards) carried out between self-hosted ICT infrastructures of suppliers and customers [23,24]. EDI and out-ofapplication methods require multiple manual interventions, lack real time supply chain visibility, and lacks synchronisation of demand and supply side information. Cloud computing in supply chains eliminates many delays that occur because of lack of integrated information sources and related manual processes required [23,24].

The virtual enterprise model of supply chain can be implemented highly effectively through cloud computing because the applications, their underlying workflow engines, and the databases are integrated with consolidated records stored by multiple supply chain agents [23,24]. Achieving highly integrated supply chain virtual enterprise with high levels of accuracy and responsiveness (linked with effectiveness and efficiency, respectively) is a new research area and is currently at conceptual stage. There are few research studies on how this can be implemented practically. Hence, currently the knowledge about supply chain virtual enterprise through cloud computing is not standardised amidst lack of actionable designs, approaches, and implementation planning. The existing studies have focussed on service-orientation concepts of supply chain applications and their components on the cloud computing. As reviewed in the next section, the concept of virtual enterprise and its realisation on cloud computing through web 2.0 service-oriented architecture and integrated processes, databases, and cloud tasks have been presented by the existing studies. However, existing studies on cloud-based enterprise architectures have not yet integrated these concepts for a realisable empirical design. Simply stated, existing studies have not investigated an actual framework of integration if virtual enterprise on cloud computing is extended to supply chains. In the absence of this framework, the limitations of traditional EDI and out-of-application methods cannot be eliminated effectively. This is justified as the following:

In absence of virtual enterprise architecture, suppliers and buyers will continue to operate as standalone virtual entities on the cloud computing. While their internal processes will be improved, collaboration and communications among them will require manual interventions. Perhaps, they may need EDI and out-of-application methods on the clouds. Their databases will be distributed and hence will lack an integrated real time visibility into the supply chain flows. The information units cannot be synchronised effectively between the suppliers and the buyers. Above all, there will be a very serious limitation. Because of disintegrated application processes and databases, the suppliers and buyers will lack dynamic abilities to quickly respond to dynamics and risks in their supply chains.

To extend the concept of virtual enterprise architecture to supply chains, it is important that the suppliers and buyers should form an integrated virtual organisation through a complex framework of strategic agreements (framework agreements) enabling them to operate as a single virtual entity. This is itself a complex phenomenon and requires separate studies. Assuming that the framework of agreements is already in place, some studies need to delve deep into how their 
application processes and tasks will interact to truly enact the virtual enterprise on cloud computing. This is another focus area lacking in existing studies.

This study has been designed to model architecture of a virtual enterprise architecture supply chain (VEASC) on cloud computing. To study the model, multiple transactions have been configured and simulated in accordance with an application called INTEND. The overall performance levels studied through simulations reflect how a supply chain virtual enterprise can ensure high accuracy and responsiveness through cloud computing for the VEASC model. The next section presents a review of supply chains on the clouds.

\section{Supply Chains ANd Cloud Computing}

\subsection{Introducing Cloud Computing}

Cloud computing systems are consolidated architectures comprising thousands of servers, storage, and network systems interconnected through services oriented infrastructures, mostly run by service providers [25, 26]. Service orientation is achieved through virtualisation of servers and networking and through orchestration of computing, storage, and networking resources [25, 26]. Services are delivered through web services aggregators, service allocators, and dispatchers [25, 26]. The users are connected to applications through software as a service (SaaS) and the developers are connected to platforms through platforms as a service (PaaS). Both SaaS and PaaS systems run on infrastructure as a service (IaaS) [25, 26].

The services are offered to subscribers of cloud services through restricted access controls and security controls $[27,28]$. The subscription data is stored in cloud-based registries that comprise of the details of cloud subscribers and their access permissions [27,28]. The services contributors to the cloud offer Java or XML (extensible mark-up language) based interfaces to their application services [27,28]. The details of all such service interfaces on the cloud are stored in the service registries maintained under the service aggregators [27,28]. More details of such service-oriented applications are presented in the Section 3.

\subsection{Enterprise Architecture on Cloud Computing}

Before entering the next level of review about deploying enterprise architecture supply chains on the clouds, a brief review of enterprise architecture on cloud computing is presented. Cloud computing may be viewed as a service-oriented clustered and homogeneous platform that can be used as a foundation of the original enterprise architecture design [29]. The ICT infrastructure on cloud computing is elastic, dynamic, adaptive, lean, agile, optimised, and always available [29]. It can enable the enterprise architecture design because it is suitable for integrating business, data, technology, and application architectures on the same platform [29]. The processes on clouds are continuous and parallel as they need not be broken into individual discrete threads running on multiple self-hosted ICT systems and executed separately [29]. Cloud computing can run data intensive applications ubiquitously from laptops, computers, mobile devices, and pervasive devices, and query massive and distributed databases through concurrent distributed XML query threads [30]. 


\subsection{Supply Chains on Cloud Computing}

Supply chain echelons are integrated through cloud computing using specially designed applications that use web services and virtualisation [24][26,27]. Cloud computing enables the virtual enterprise model of supply chains in which, suppliers and manufacturers can form strategic arrangements with profit sharing, benefits sharing, innovations sharing, resources sharing, and risks sharing for shared access to the markets [31][38]. The workflow applications systems of multiple suppliers can be integrated through PaS application development and delivery of runtimes [31]. The inter-systems communications are facilitated through standard $\mathrm{XML}$ and the users to systems communications are facilitated through Web 2.0 interfaces programmed on HTML 5.0 [25][32].

Integration through virtual enterprise requires extensive collaborations and communications among all the supply chain echelons and the support functions supporting them [1]. For ensuring long-term strategic relationships among supply chain partners, communications and collaborations need to penetrate through the organisational boundaries at all the levels of the organisational hierarchies [33]. The processes and their tasks among the supply chain partners are executed the way a massive single business enterprise operates [33]. The integration is required at the strategic level among the top management groups, at the tactical level among the middle management groups, and at the operations level at the lower management groups [34]. The entire framework should be globally operated and accessible [34].

Web services through clouds facilitate global integration of all participating organisations in the virtual enterprise and facilitate a single, large, and centralised platform for information entry and management, information processing, and information sharing [35,36,37]. The suppliers and manufacturers can use the global Inter-enabled platform for enhancing competitive value, innovation value, learning value, knowledge value, and financial value [38].

In the past, Internet has helped in establishing and integrating major workflows of a supply chain in the areas of materials requirements planning, procurements, scheduling of production and postproduction tasks, strategic supplier relationships, and inventory control. Traditionally, electronic data interchange (EDI) between the suppliers' ICT systems and manufacturers' production and materials planning systems over private links or Internet has been the established system for information sharing [39]. Cloud computing is the next step when real-time transactions, collaborations, and communications have replaced EDI [40]. EDI required integration with internal and external applications for automating the transactions and enabling real-time visibility into the supply chain events [23] [40]. Further, EDI required to break the strong hierarchical boundaries of information domains and was operated at individual systems level rather than enterprise level [23] [40].

The review in this section reflects that existing studies have recognised the limitations of traditional methods and the value of virtual enterprise integration on cloud computing to eliminate those limitations. However, an empirical framework for achieving it in real world supply chains has not evolved. The technical knowledge is already formed in the cloud computing literature. A researcher needs to extend this knowledge in forming an empirical model of virtual enterprise architecture for supply chains by exploiting the integration abilities of cloud computing. A practical insight is needed into the service-oriented designs for achieving a virtual enterprise of integrated suppliers and buyers. To gain a better understanding, a review of service- 
oriented applications integration on cloud computing is presented in the next section. This part of the review has also helped in modelling a multi-party supply chain application in OPNET.

\section{Service-Oriented Applications integration on the Cloud COMPUTING}

Service-orientation in supply chain can help in requesting a service offered by any participating organisation on the cloud and the cloud system ensures that the service is searched and delivered to the requester [31]. For example, by simply executing queries written in XML web services description language, a procurement manager can fetch information on current products in the catalogue, their availability in the inventories of the connected suppliers, prices and discounts offered by the suppliers offering the product, location of the products, and expected lead time of delivery [28][31]. Cloud computing is a virtualised ICT infrastructure having multiple virtual domains each owned by a participating organisation [41]. The databases managed by the participating organisation can be deployed on the cloud as a public service or run within the virtual domains of the respective owners [41]. In either scenario, the databases can run on multiple servers in parallel through parallel processing [41]. Hence, real time queries can be run on them without conducting EDI between the servers and the users [41]. For example, the product master databases, price master databases, ordering databases, and invoicing transactions databases managed by multiple organisations can be deployed on the same cloud [41]. An integrated XML query can be used to run on multiple databases in parallel and provide the output into a temporary data view space provided to the requester [41].

The applications, collaborations, and communications workflows can be integrated on cloud computing [42]. For example, collaborations can be designed on schedules, events, marketing, budgets and expenses, financial statements, presentations, task managers and monitors, web databases and spreadsheets, web apps, file sharing, web mails, web conferencing, online groupware, wikis, blogs, and social networking [42]. Hence, when a process task is in progress, all participants related to the task can have real time access to all resources and data to execute it [42]. Participants in the task can be hooked in real time irrespective of their location [42]. Natural language processing and time-zone management can break the barriers of multilingual and multicultural international integration [42]. This model may be viewed as value focussed process engineering, which integrates business constructs, risk management, business objectives, and objectives hierarchy of multiple organisations while a common task is being processed [43]. The integration comprises inter and intra-organisational process integration, operations integration, online cognitive integration, and collaborative integration [43]. This is like integrating physical, spatial, and temporal flows in the supply chain [43].

The choice of XML for processing, storing, and querying information is to ensure loose connections between the information presentation and the databases [28]. Many databases are stored in the form of XML data files, which have relational capabilities and supports parallel processing [28]. Data tables in modern databases can be exported into XML data files [44]. The XML data files are used in mobile data views as they can be fast and easily accessible through mobile apps running SOAP (simple object access protocol) engine [45]. SOAP can directly query XML data files [45]. SOAP can facilitate distributed and concurrent execution of XML scripts, XML threads, and execution libraries [25]. The applications hosted by contributing organisations to the web services infrastructure can have their XML data files spread across the cloud with 
executions confined within the virtual boundaries [45]. These data files can be accessed through an SOAP apps-based light weight query execution from mobile phones [46], and also from desktop computers with SOAP engine deployed [47]. A user can query data files of multiple contributing organisations concurrently and quickly gain consolidated data views presenting integration information from multiple parties as needed in the task under process [42].

The database objects on the cloud computing are distributed among the server arrays spread across the world $[48,49,50]$. The locations of the database objects and their ownership details are allocated by the cloud resource manager and their details are stored in cloud objects registries $[48,49,50]$. The service allocation and dispatching agents can query the registries for identifying the locations of the database objects such that the queries can be broken into threads and sent to the objects for parallel query processing $[48,49,50]$. The registries also are XML DTD files with hierarchical structures, which help in identifying the objects against user requests and also help in negotiating access levels and service levels based on the subscription details of the users $[48,49,50]$. The runtime environments of the databases are allocated to users through their respective virtual machines, which comprises tools for building queries and data views generated after the queries are run in parallel on all the database objects throughout the cloud $[48,49,50]$.

The concepts of technical design of a virtual enterprise using service-oriented architecture are adequately established in cloud computing literature. Assuming that a framework of integration agreements among multiple buyers and suppliers has been formed, a deeper view into the actual interactions of virtual enterprise applications is investigated in this research. The interactions should be planned carefully to ensure that there is no need for EDI and out-of-application methods within the framework such that their limitations stated in Section 1 are fully eliminated in the design.

With the above theoretical background, a cloud has been modelled in OPNET tool with some of the supply chain transactional processing in a commercial application, called INTEND, were modelled. The model is described in Section 5. The next section (Section 4) presents the research approach used in this research.

\section{THE RESEARCH APPROACH}

The research approach used in this research is modelling and simulations. The workflow for data collection and analysis used for this research is presented in Figure 2: 


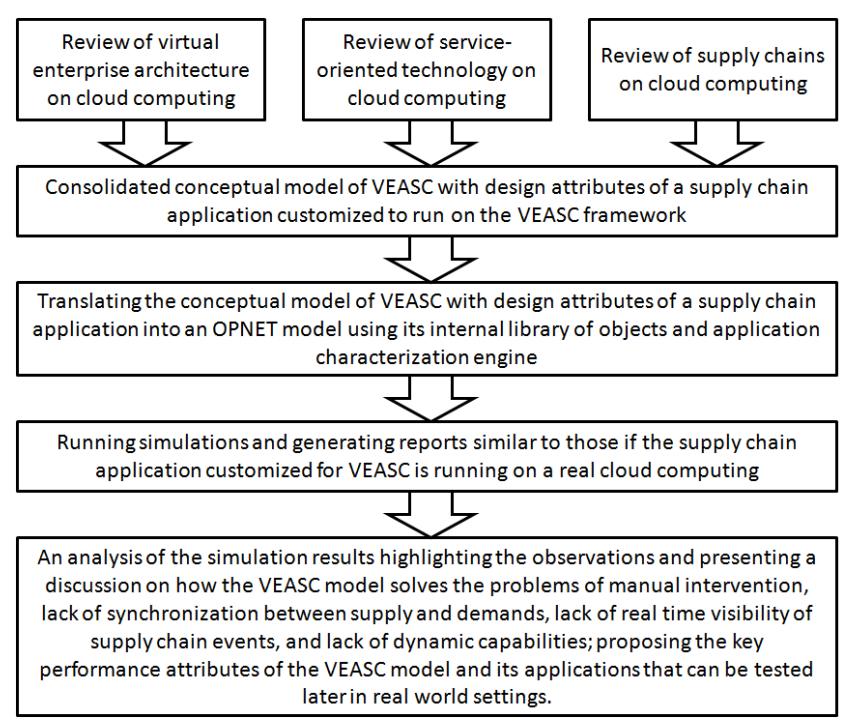

Figure 2: Workflow for data collection and analysis

The tool chosen for the research is OPNET, which is suitable for creating virtual test bed environment for ICT infrastructures and the applications running on them [51,52]. The tool is primarily a commercial network analytics engine used for designing, testing, and optimizing ICT infrastructures [51,52]. The academic version is available through OPNET university program, which limits simulation to 50 million events. The academic version contains most of the libraries of the commercial version and has features suitable for virtual test beds for academic applications. The libraries comprise of generalised objects supporting all technological attributes needed to model an ICT infrastructure, and also comprise of common commercial vendor model of products that can be configured the way the vendors have designed them.

In this research, a cloud comprising suppliers and procurement groups have been designed. More supply chain agents could have been modelled, but this design is sufficient to present the concept presented in this study. The server model objects are chosen from the OPNET library and interconnected through advanced switches to form the cloud. The supply chain applications and databases have been configured using the application and profile configuration objects and the supply chain transactions are configured using the custom application configuration object. The simulation span is 12 hours and the report comprises a number of parameters chosen. The traffic has been configured as exponential with standard predefined mean values as suggested by OPNET depending upon the loading profile selected in the application configuration object. By default the loading is chosen as high on all the databases supporting the application. Some deliberate delays have been introduced between two types of transactions. For example, the delay between delivery and invoicing has been configured as a minimum of one hour. The actual results depend upon the way the network is behaving while the transactions by all agents are in progress.

OPNET generates hundreds of reports after simulation. Given the limited space in this report, only the most relevant reports are shown. Given that reports related to all the devices on the cloud cannot be shown in the limited space on this document, only some samples have chosen. The full set of reports can be presented on request. The reports reflect the internal interactions between the supply chain agents through the applications and the databases. 


\section{Modelling Strategic Supplier Contracts on the Cloud}

The cloud model for virtual enterprise supply chain is as presented in Figure 2. This cloud is formed by Cisco Cat 6000 enterprise class switches and Compaq GS 320 enterprise class servers. In real world, these are high-end machines and hence have been perceived to be suitable for building a high performing cloud. The links are gigabit Ethernet links that can carry up to 1000 Mbps of data traffic. The capacity can be increased by adding more connections or using other faster technologies (like 10G and ATM). These links are available in OPNET objects library.

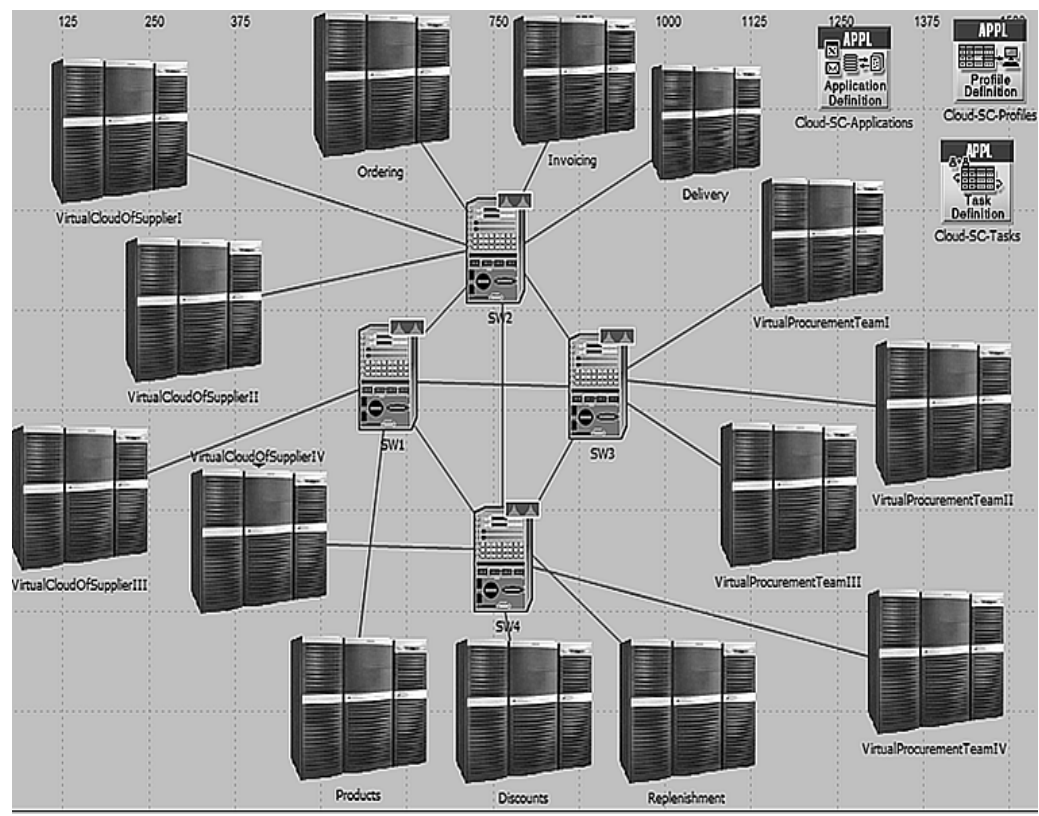

Figure 3: Cloud model for virtual enterprise supply chain designed in OPNET

The supply chain application modelled in this cloud is related to strategic supplier management in a virtual enterprise model. In the model four groups of suppliers (Virtual Cloud of Supplier I to Virtual Cloud of Supplier IV) and four groups of procurement teams (Virtual Procurement Team I to Virtual Procurement Team IV) are created. Each of the supplier group and procurement team is allocated one Compaq GS 320 server. In real clouds, there may be hundreds of servers allocated to them for running their applications. In addition to the suppliers and the procurement teams, one Compaq GS 320 server each is allocated to databases of ordering, invoicing, delivery, products, discounts, and replenishment.

A common application system is configured on the cloud. This application is called Procurement Process. It has a workflow comprising multiple phases of activities as described in Table 1. This workflow is configured using the custom application object in OPNET. OPNET has a process engine built within the custom application tool that can be used to configure significantly large workflows. For each phase of the workflow, a task is defined. The action taken on model (during simulations) is based on the tasks and also the design. For example, the database object named products DB is configured on the ordering server and the client runtime is configured on the servers for the procurement officers' and suppliers' groups. The cloud should be able to identify 
this server when the query executions on products DB are requested. In OPNET modelling, the identification is carried out through a destination preferences setting in each of the requesting server. This object configuration comprises records of all the application components and their respective destination servers. This may be viewed as similar to the services registry on cloud computing.

Table 1: The process for operating the framework agreement

\begin{tabular}{|c|c|c|}
\hline $\begin{array}{l}\text { Phase } \\
\text { no. }\end{array}$ & Task Description & Action on the cloud \\
\hline 1 & $\begin{array}{l}\text { The procurement team retrieves details and } \\
\text { identification of the products that they planned } \\
\text { to order. The service request is made to the } \\
\text { products database. }\end{array}$ & $\begin{array}{l}\text { The cloud dispatcher identifies the database } \\
\text { objects pertaining to products DB and } \\
\text { allocates the query to them. The query } \\
\text { enters a queue waiting for its turn before } \\
\text { other queries are executed. }\end{array}$ \\
\hline 2 & The products DB replies to the service request. & $\begin{array}{l}\text { All the details of the products requested by } \\
\text { the procurement team are displayed on the } \\
\text { application screen (example, an ordering } \\
\text { form). }\end{array}$ \\
\hline 3 & $\begin{array}{l}\text { The procurement team retrieves details and } \\
\text { identification of the products' prices and } \\
\text { discounts that they planned to order. The } \\
\text { service request is made to the discounts } \\
\text { database. }\end{array}$ & $\begin{array}{l}\text { The cloud dispatcher identifies the database } \\
\text { objects pertaining to discounts DB and } \\
\text { allocates the query to them. The query } \\
\text { enters a queue waiting for its turn before } \\
\text { other queries are executed. }\end{array}$ \\
\hline 4 & $\begin{array}{l}\text { The discounts DB replies to the service } \\
\text { request. }\end{array}$ & $\begin{array}{l}\text { All the details of the products' prices and } \\
\text { discounts requested by the procurement } \\
\text { team are displayed on the application } \\
\text { screen (example, an ordering form). }\end{array}$ \\
\hline 5 & $\begin{array}{l}\text { The procurement team retrieves details and } \\
\text { identification of the products' stocks that they } \\
\text { planned to order. The service request is made } \\
\text { to the replenishment database. }\end{array}$ & $\begin{array}{l}\text { The cloud dispatcher identifies the database } \\
\text { objects pertaining to replenishment DB and } \\
\text { allocates the query to them. The query } \\
\text { enters a queue waiting for its turn before } \\
\text { other queries are executed. }\end{array}$ \\
\hline 6 & $\begin{array}{l}\text { The replenishment DB replies to the service } \\
\text { request. }\end{array}$ & $\begin{array}{l}\text { All the details of the products' stocks } \\
\text { requested by the procurement team are } \\
\text { displayed on the application screen } \\
\text { (example, an ordering form). }\end{array}$ \\
\hline 7 & $\begin{array}{l}\text { The procurement team retrieves details and } \\
\text { identification of the products' delivery lead } \\
\text { times that they planned to order. The service } \\
\text { request is made to the delivery database. }\end{array}$ & $\begin{array}{l}\text { The cloud dispatcher identifies the database } \\
\text { objects pertaining to delivery DB and } \\
\text { allocates the query to them. The query } \\
\text { enters a queue waiting for its turn before } \\
\text { other queries are executed. }\end{array}$ \\
\hline 8 & The delivery DB replies to the service request. & $\begin{array}{l}\text { All the details of the products' delivery } \\
\text { lead times requested by the procurement } \\
\text { team are displayed on the application } \\
\text { screen (example, an ordering form). }\end{array}$ \\
\hline 9 & $\begin{array}{l}\text { The procurement team now completes the first } \\
\text { order and saves in the ordering database. This }\end{array}$ & $\begin{array}{l}\text { The cloud dispatcher identifies the database } \\
\text { objects pertaining to ordering DB and }\end{array}$ \\
\hline
\end{tabular}




\begin{tabular}{|c|c|c|}
\hline Phase & Task Description & Action on the cloud \\
\hline & is called PO1. & $\begin{array}{l}\text { sends the PO1 data to be saved in the } \\
\text { objects. }\end{array}$ \\
\hline 10 & $\begin{array}{l}\text { The procurement team now completes the } \\
\text { second order and saves in the ordering } \\
\text { database. This is called } \mathrm{PO} 2 \text {. }\end{array}$ & $\begin{array}{l}\text { The cloud dispatcher identifies the database } \\
\text { objects pertaining to ordering DB and } \\
\text { sends the PO2 data to be saved in the } \\
\text { objects. }\end{array}$ \\
\hline \multicolumn{3}{|c|}{ The subsequent transactions are carried out by the suppliers' group. } \\
\hline 11 & $\begin{array}{l}\text { The supplier team gets access to the order } \\
\text { details by running a query on the ordering DB. }\end{array}$ & $\begin{array}{l}\text { The cloud dispatcher identifies the database } \\
\text { objects pertaining to ordering DB and } \\
\text { allocates the query to them. The query } \\
\text { enters a queue waiting for its turn before } \\
\text { other queries are executed. }\end{array}$ \\
\hline 12 & The ordering DB replies to the service request. & $\begin{array}{l}\text { All the details of the orders placed by the } \\
\text { procurement team are displayed on the } \\
\text { application screen (example, an order } \\
\text { execution form). }\end{array}$ \\
\hline 13 & $\begin{array}{l}\text { Supplier group issues delivery instructions that } \\
\text { are saved in the delivery DB. This is Delivery } \\
1 \text { against PO } 1 .\end{array}$ & $\begin{array}{l}\text { The cloud dispatcher identifies the database } \\
\text { objects pertaining to delivery DB and sends } \\
\text { the Delivery } 1 \text { data to be saved in the } \\
\text { objects. }\end{array}$ \\
\hline 14 & $\begin{array}{l}\text { Supplier group issues delivery instructions that } \\
\text { are saved in the delivery DB. This is Delivery } \\
2 \text { against PO } 2 \text {. }\end{array}$ & $\begin{array}{l}\text { The cloud dispatcher identifies the database } \\
\text { objects pertaining to delivery DB and sends } \\
\text { the Delivery } 2 \text { data to be saved in the } \\
\text { objects. }\end{array}$ \\
\hline 15 & $\begin{array}{l}\text { Once the dispatch is confirmed (an automatic } \\
\text { notification about Delivery } 1 \text { from the delivery } \\
\text { team; not modelled in this workflow), the } \\
\text { Invoice } 1 \text { is generated. }\end{array}$ & $\begin{array}{l}\text { The cloud dispatcher identifies the database } \\
\text { objects pertaining to Invoicing DB and } \\
\text { sends the Invoicing } 1 \text { data to be saved in } \\
\text { the objects. }\end{array}$ \\
\hline 16 & $\begin{array}{l}\text { Once the dispatch is confirmed (an automatic } \\
\text { notification about Delivery } 2 \text { from the delivery } \\
\text { team; not modelled in this workflow), the } \\
\text { Invoice } 2 \text { is generated. }\end{array}$ & $\begin{array}{l}\text { The cloud dispatcher identifies the database } \\
\text { objects pertaining to Invoicing DB and } \\
\text { sends the Invoicing } 2 \text { data to be saved in } \\
\text { the objects. }\end{array}$ \\
\hline \multicolumn{3}{|c|}{ The subsequent transactions are carried out by the procurement team } \\
\hline 17 & $\begin{array}{l}\text { The procurement team runs a query on the } \\
\text { replenishment database to know the change in } \\
\text { stocks of the products at the buyers end and } \\
\text { also at the suppliers end. This is done to plan } \\
\text { for the next ordering cycle. }\end{array}$ & $\begin{array}{l}\text { The cloud dispatcher identifies the database } \\
\text { objects pertaining to replenishment DB and } \\
\text { allocates the query to them. The query } \\
\text { enters a queue waiting for its turn before } \\
\text { other queries are executed. }\end{array}$ \\
\hline 18 & $\begin{array}{l}\text { The replenishment DB replies to the service } \\
\text { request. }\end{array}$ & $\begin{array}{l}\text { The details of stocks at the buyers' and } \\
\text { customers' ends are displayed on the screen } \\
\text { (like, replenishment form). }\end{array}$ \\
\hline
\end{tabular}

This workflow is formed with the help of a running procurement application named INTEND in the researcher's organisation. For modelling this application, some of the steps in the original application have been eliminated to make it simple and relevant. In real world, the workflow will be much more advanced and complex. For example, the workflows of packaging, transportation, materials inspection reporting, and later running a forecasting module for replenishment can be added in this workflow. However, the purpose of this study is to investigate how an integrated workflow for integrated suppliers and procurement teams of multiple organisations on the cloud 
works for the VEASC model. Hence, the workflow has been kept shorter than the original application. In the next section, the simulation results have been presented and analysed.

\section{Simulation Results}

The workflow is simulated with 100 users load on each cloud server (400 users in suppliers' groups and 400 users in the procurement teams). The model is simulated assuming that all the users are online on the cloud operating their transactions. The simulation screenshot in Figure 3 shows the results of three phases of the procurement process cloud application: ordering, delivery, and invoicing.

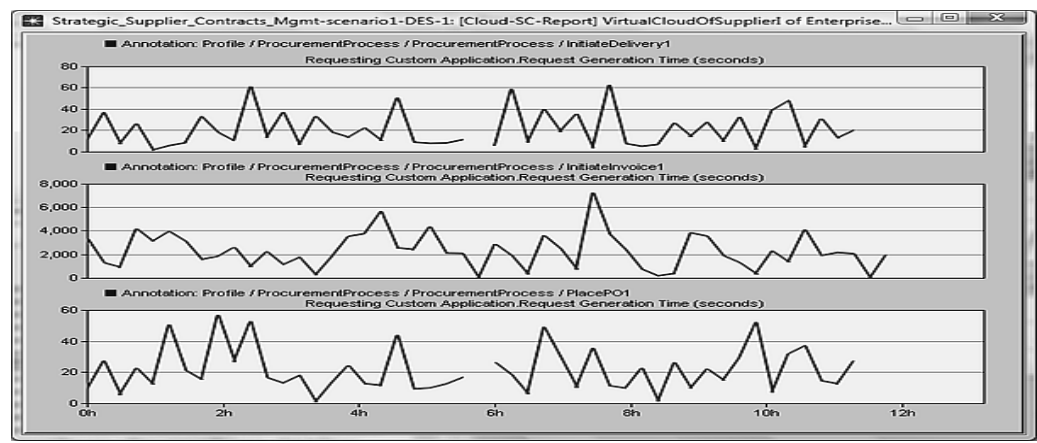

Figure 4: Simulation results of three phases of the cloud application for the first servers of suppliers and procurement groups

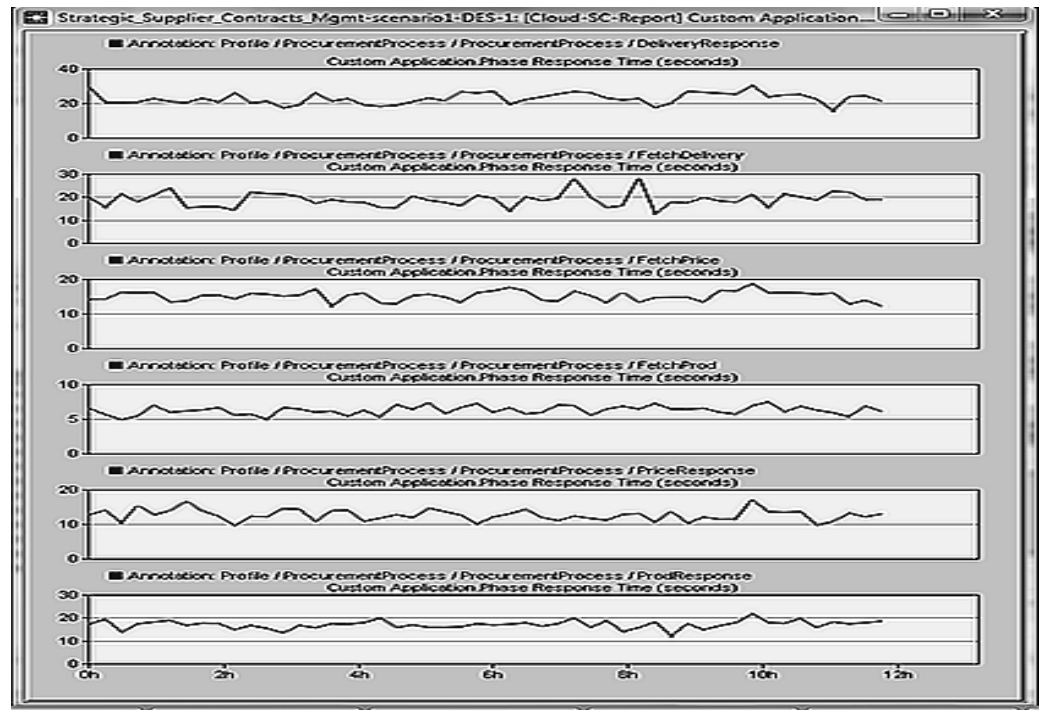

Figure 5: Simulation results of some of the process threads comprising query initiations and query responses

The delivery initiation transactions are occurring almost concurrently with the ordering initiation transactions (Figure 4). The invoice initiation transactions are occurring within couple of hours assuming that the stock verification and delivery instructions are issued within this period. The phases of packaging, transportation, delivery, and materials inspection are present in the INTEND 
application but eliminated here because they will require a few days of simulations, which is not possible in the academic edition (the academic edition of OPNET allows 50 million events in the simulation). In this research, the simulation carried out is of about 12 hours. The process names (like, FetchProd, FetchDelivery, PriceResponse, and ProdResponse) have been taken from the INTEND application. The results show concurrency of transactions executing all phases within the range of zero to 40 seconds. This performance is evident while there are four supplier organisations and four buying organisations collaborating and coordinating through this cloud.

While the phases of the strategic supplier management are executing for eight organisations comprising hundred users each, there have not been any stress on the databases. Simulation results of databases revealed that the average load is mostly in a few hundred milliseconds. How are these observations relevant to VEASC? A discussion and analysis in this context has been presented in the next section (Section 7).

\section{DiscuSSION AND ANALYSIS}

The VEASC model requires integration of all supply chain agents to a common synchronised framework of coordination, collaboration, and communications. Traditionally, the framework has been unsynchronised because of methods like EDI, e-mailing, posting updates, and live communications needing human interventions for completing all the phases of the supply chain processes. This may cause lower effectiveness and efficiency because of high dependence on speed of human responses. This problem has been reduced in cloud-based VEASC as the transactions are interconnected through the cloud without any manual system needed. Figure 5 shows almost continuous execution of tasks through integrated application instances and databases. There is no manual information sharing because the databases are relational and interconnected. For example, as soon as the suppliers update the stocks details, they are accessible to the procurement managers. There is no need for an EDI to share this information.

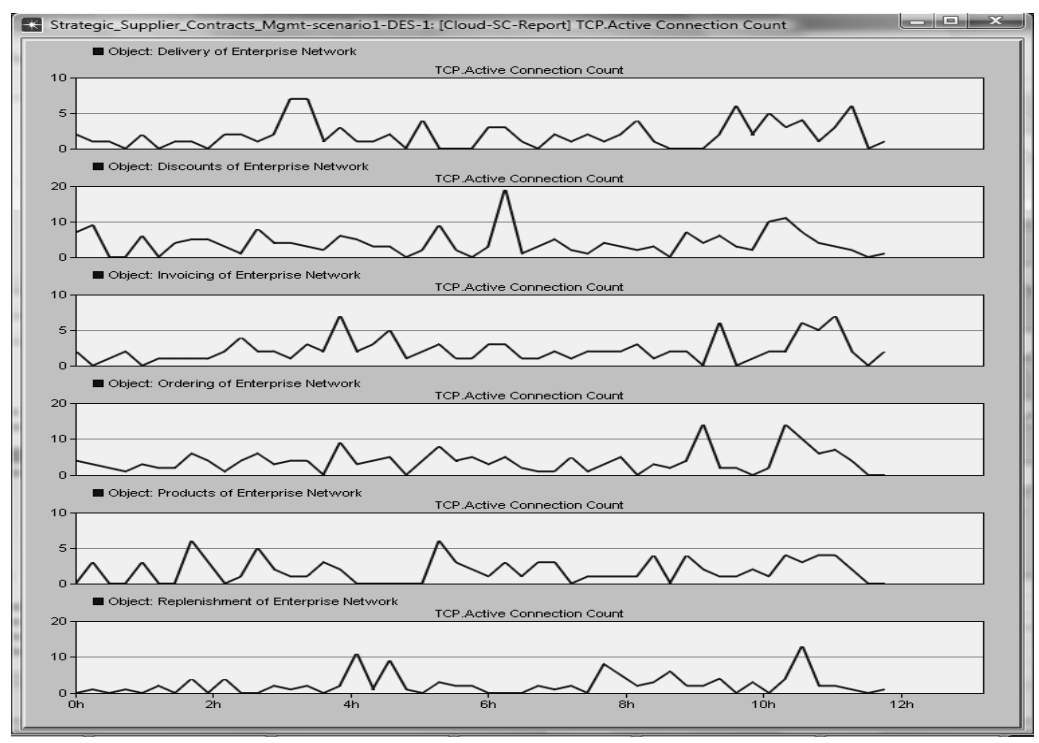

Figure 6: Number of active TCP sessions reflecting the active concurrent transactions occurring on the cloud databases 
Figure 6 presents how the ordering application can access multiple databases simultaneously. The objects of these databases are in reality maintained by multiple organisations. In real clouds, they will be dynamically updating XML data files spread across thousands of servers on the cloud. The transactions shown in Figure 7 are merely queries and data commits through SOAP. In the real world VEASC, all the supply chain functions can have their respective XML data files accessible to other agents. Separate XML data files may be used for collaboration and communications having records integrated with the integrated cloud views. Free text records, images, voice, and video files can be a part of the records presented in the data views. For example, while approving a payment an agent can view the order, the invoice, the delivery report, the inspection report with a video showing the inspections, and free text records entered by all supply agents involved in that order.

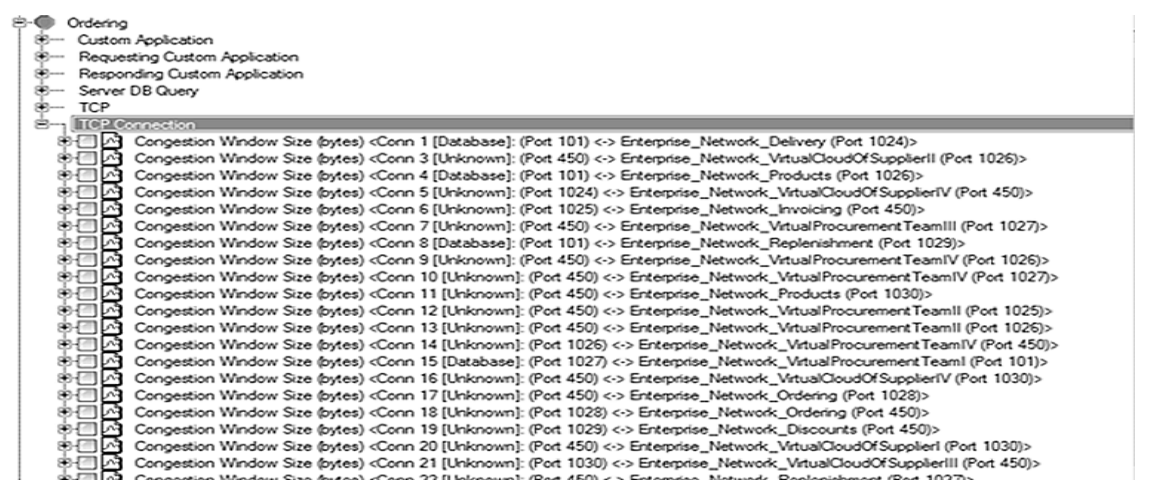

Figure 7: A screen shot showing part of all the TCP connections occurring on the cloud

The INTEND application modelled in this report currently lacks these features because it is not cloud-enabled. Hence, many out-of-application collaboration tools are needed (like e-mails and chat boards). The records of such collaborations and communications are not recorded within INTEND because of lack of integration such tools. This gap can lead to communication gaps while the content is available somewhere else but not readily accessible. The proposed model of cloud application can support VEASC because every possible transaction and collaboration/communication record can be accessible through the same record ID. This model makes every supply chain agent integrated and synchronised. There is little scope for manual intervention by individuals as the system integration is driving the transactions. The agents need to simply keep clearing their transactional queues as a routine. The participating agents can benefit from the shared values of the VEASC model. In this model every agent can avail repeatability, commonality, proportionality, value-sharing, shared risk management, shared advancements, and shared innovations. These are performance attributes projected for the proposed VEASC model, as explained below:

(a) Repeatability: The business processes and their tasks are closely integrated through shared cloud objects such that the results of committed transactions become shared knowledge entities. The knowledge and experience in handling them can be reused by all the members of the virtual enterprise thus enabling a gradual path of maturity.

(b) Commonality: The business processes and tasks can be standardised by establishing common conventions, codes, methods, and protocols (within the shared cloud objects) 
followed by each member of the virtual enterprise. No delays shall occur in translations or transformations of processes and tasks between any two entities.

(c) Proportionality: The volumes of transactions shall be proportionately distributed among the participating members depending upon their partnership share translating into proportionately shared benefits.

(d) Value-sharing: The value streams generated by this system shall be shared by all members as they are using a common service-oriented structure comprising shared cloud objects.

(e) Shared risk management: All members in the virtual enterprise will share common risks, as they are operating common business processes and sharing their cloud objects and databases on a common cloud platform. For example, if the application tasks listed in Table 1 are exploited by an attacker, or certain application processes fail, every member will face the resulting impacts.

(f) Shared advancements: Advancements in this system will benefit all members because of shared business processes and tasks.

(g) Shared innovations: The members of the virtual enterprise can jointly evolve new innovations in this system through shared research and development.

It is projected that this system is capable of automation, real time visibility into the supply chain events, close synchronisation of data generated by suppliers and buyers (as they are integrated within the virtual enterprise), and is capable of developing dynamic capabilities (quick response and agility) to face supply chain dynamism and uncertainties. Integrated cloud objects do not leave any room for delays in business processes, as reflected in Figures 4 and 5. In a traditional supply chain, the transactions of ordering and delivery initiation may be days apart. In this system, a delivery initiation occurs within a few seconds after order confirmation because of tightly integrated cloud objects. Further, there are no manual processes of negotiations, ordering, order confirmation, stock checking, and such other interactions requiring human intervention. With these projected claims, it is hereby suggested that simulations may not be a true reflection of actual performance of this system. There may be multiple practical challenges in operating the VEASC model in real supply chains. The simulation results have not highlighted such challenges in this study, because all transactions are modelled to be successful in their first instances. In real cloud applications, there may be chances of exclusive locks in databases, object corruptions, data corruptions, failure of certain threads, or even failure of hardware. The changes needed in the process flow to quickly detect such failures and activate remedies should be investigated further. In a fully automated system, instant identification of errors and failures and activation of quick remedies are highly critical.

\section{Conclusions}

In this study, a cloud computing model for enabling VEASC model of supply chain has been studied with the help of modulation and simulations in OPNET. The simulations revealed close synchronisation of all the phases of a procurement process because the application seamlessly interacts with the databases contributed by all the suppliers and buyers connected to the cloud. 
The model ensures full automation with human tasks directed by systemic integration rather than individual interventions. This architecture can be suitable for strategic integration of all the echelons of a supply chains extended to all suppliers and customers. The transactions flow automatically both ways without any manual interventions. This cloud-enabled VEASC model of supply chain can be used for strategic market integration with every contributing agent sharing all the benefits of the collaboration. This model can enable competitiveness among suppliers, collaboration among multiple suppliers for serving common customers, auctions, online tendering, automated volume commitments based on replenishment records and forecasting, and such other functions. It can potentially enable automation, real time visibility into the supply chain events, synchronisation of demand and supply side data, and dynamic capabilities to face supply chain dynamics and uncertainties. The model reflects possibility of repeatability, commonality, proportionality, value-sharing, risk management, advancements, and innovations for all the contributing members. However, given that this research was simulation-based, all these projected possibilities need to be tested in a real world supply chain.

\section{REFERENCES}

[1] Christopher, M.: Logistics \& Supply Chain Management, 4th Edition, Prentice Hall Global (2011)

[2] Chopra, S. \& Meindl, P.: Supply Chain Management - Strategy, Planning, and Operation, Fourth Pearson International Edition, Worldwide: Pearson (2010)

[3] Cousins, P., Lamming, R., Lawson, B., \& Squire, B.: Strategic Supply Management: Principles, Theories, \& Practices, London: Pearson (2008)

[4] Surie, C. \& Wagner, M.: Supply Chain Analysis, p. 37-64, Book Chapter: Supply Chain Management and Advanced Planning, 3rd Edition, Stadtler, H. \& Kilger, C (Eds), Springer, Heidelberg (2005)

[5] Meyr, H. \&Stadtler, H.: Types of supply chains, p. 65-80, Book Chapter: Supply Chain Management and Advanced Planning, 3rd Edition, Stadtler, H. \& Kilger, C (Eds), Springer, Heidelberg (2005)

[6] Gunasekaran, A., Lai, K., \& Cheng, T. C. E.: Responsive supply chain:A competitive strategy in a networked economy, Omega, Vol. 36, p. 549-564, Elsevier (2008)

[7] Jeschonowski, D. P., Schmitz., Wallenburg, C. M., \& Weber, J.: Management control systems in logistics and supply chain management: a literature review, Logistics Research, 1, p. 113-127, Springer, Heidelberg (2009)

[8] Fleischmann, B. Meyr, H., \& Wagner, M.: Advanced Planning, p. 81-108, Book Chapter: Supply Chain Management and Advanced Planning, 3rd Edition, Stadtler, H. \& Kilger, C (Eds), Springer, Heidelberg (2005)

[9] Lambert, D. M., Garcia-Dastugue, S. J., \& Croxton, K. L.: An evaluation of process-oriented supply chain management frameworks, Journal of Business Logistics, 26 (1), p. 25-51 (2005)

[10] Eggert, A. \& Ulaga, W.: Managing customer share in key supplier relationships, Industrial Marketing Management, Vol. 39: p. 1346-1355, Elsevier (2010)

[11] Mena, C., Humphries, A., \& Choi, T. Y.: Toward a theory of multi-tier supply chain management, Journal of Supply Chain Management, 49 (2), p. 58-77, Wiley (2013)

[12] Piercy, N. F.: Strategic relationships between boundary-spanning functions: Aligning customer relationship management with supplier relationship management, Industrial Marketing Management, 38: p. 857-864, Elsevier (2009)

[13] Kim, D., Cavusgil, S. T., \& Calantone, R. J.: Information System Innovations and Supply Chain Management: Channel Relationships and Firm Performance, Journal of the Academy of Marketing Science, 34 (1), p. 40-54, Sage (2006)

[14] Qrunfleh, S. \& Tarafdar, M.: Supply chain information systems strategy:Impacts on supply chain performance and firm performance, International Journal of Production Economics, 147: p. 340-350, Elsevier (2014)

[15] Kim, S. W.: An investigation on the direct and indirect effect of supply chain integration on firm performance, International Journal of Production Economics, 119, p. 328-346, Elsevier (2009) 
[16] Kim, D.: Relationship between supply chain integration and performance, Operations Management Research, Vol. 6, p. 74-90, Springer (2013)

[17] Kim, D., Cavusgil, S. T., \& Calantone, R. J.: Information System Innovations and Supply Chain Management: Channel Relationships and Firm Performance, Journal of the Academy of Marketing Science, 34 (1): p. 40-54, Sage (2006)

[18] Samaranayake, P.: A conceptual framework for supply chain management: a structural integration, Supply Chain Management: An International Journal, 10 (1), p. 47-59, Emerald (2005)

[19] Attaran, M. \& Attaran, S.: Collaborative Supply Chain Management: The Most Promising Practice for Building Efficient and Sustainable Supply Chains, Business Process Management Journal, 13 (3): p. 390-404, Emerald (2007)

[20] Holweg, M., Disney, S., Holmstrom, J., \& Smaros, J.: Supply Chain Collaboration: Making Sense of the Strategy Continuum, European Management Journal, 23 (2), p. 170-181, Elsevier (2005)

[21] Simatupang, T. M. \& Sridharan, R.: Design for supply chain collaboration, Business Process Management Journal, 14 (3): p. 401-418, Emerald (2008)

[22] Jitpaiboon, T.: The Roles of Information Systems Integration in the Supply Chain Integration Context - Firm Perspective, Published Doctor of Philosophy thesis, p. 1-279, The University of Toledo, UMI Microform 3188242, ProQuest Information and Learning (2005)

[23] Cegielski, C. G., Jones-Farmer, L. A., Wu, Y., \& Hazen, B. T.: Adoption of cloud computing technologies in supply chains: An organizational information processing theory approach, The International Journal of Logistics Management, 23 (2), p. 184-211, Emerald (2012)

[24] Jun, C. \& Wei, M. Y.: The Research of Supply Chain Information Collaboration Based on Cloud Computing, Procedia Environmental Sciences, 10: p. 875-880, Elsevier (2011)

[25] Buyya, R., Vecchiola, C., \& Selvi, S. T.: Mastering Cloud Computing Foundations and Applications Programming, Worldwide: Elsevier (2013)

[26] Barry, D. K. \& Dick, D.: Web Services, Service-Oriented Architectures, and Cloud Computing, 2nd Edition, Worldwide: Elsevier (2013)

[27] Ouzzani, M. \& Bouguettaya, A.: Efficient Access to Web Services, IEEE Internet Computing: p. 3444.

[28] Srinivasan, L. \& Treadwell, J. (2005), "An Overview of Service-oriented Architecture, Web Services and Grid Computing", p. 1-13, HP Research (2004)

[29] Raj, P. \& Periasamy, M.: The convergence of enterprise architecture (EA) and cloud computing, p. 61-90, Book Chapter: Cloud Computing for Enterprise Architectures, Mahmood, Z. \& Hill, R. (Eds.), Springer, Heidelberg (2011)

[30] Rao, N. R.: The convergence of enterprise architecture (EA) and cloud computing, p. 159-172, Book Chapter: Cloud Computing for Enterprise Architectures", Mahmood, Z. \& Hill, R. (Eds.), Springer, Heidelberg (2011)

[31] Grilo, A, \& Jardim-Gonclaves, R.: Cloud-Marketplaces: distributed e-procurement for the AEC sector, Advanced Engineering Informatics, vol. 27, p. 160-172, (2013)

[32] Ferguson, D. F. \& Hadar, E.: Optimizing the IT business supply chain utilizing cloud computing, In 2011 8th International Conference \& Expo on Emerging Technologies for a Smarter World (CEWIT), 2-3 Nov. 2011, New York, p. 1-6, IEEE (2011)

[33] Jun, C \& Wei, M. Y.: The research of supply chain information collaboration based on cloud computing, 3rd International Conference on Environmental Science and Information Application Technology (ESIAT 2011), Procedia Environmental Sciences, 10, pp. 875-880 (2011)

[34] Prajago, D \& Olhager, J.: Supply chain integration and performance: the effects of long-term relationships, information technology and sharing, and logistics integration, International Journal of Production Economics, 135, p. 514-522 (2012)

[35] Wu, I, Chuang, C, \& Hsu, C.: Information sharing and collaborative behaviors in enabling supply chain performance: a social exchange perspective, International Journal of Production Economics, 148, p. 122-132 (2014)

[36] Monczka, R. M., Handfield, R. B., Giunipero, L. C. \& Patterson, J. L.:, Purchasing and Supply Chain Management, 4th Edition, Cengage Learning Canada (2009) 
[37] Meixell, M. J. \& Gargeya, V. B.: Global supply chain design: A literature review and critique, Transportation Research Part E, 41, p. 531-550 (2005)

[38] Walters, P. G. P.: Adding value in global B2B supply chains: Strategic directions and the role of the Internet as a driver of competitive advantage, Industrial Marketing Management, 37, p. 59-68, Elsevier (2008)

[39] Lancioni, R. A., Smith, M. F., \& Oliva, T. A.: The Role of the Internet in Supply Chain Management, Industrial Marketing Management, 29, 45-56, Elsevier (2000)

[40] Ranganathan, C., Teo, T. S. H., \& Dhaliwal, J.: Web-enabled supply chain management: Key antecedents and performance impacts, International Journal of Information Management, 31: p. 533545, Elsevier (2011)

[41] Kiroski, K., Gusev, M., \& Ristov, S: IaaS Cloud Model for e-Ordering and e-Invoicing, In 2013 Federated Conference on Computer Science and Information Systems (FedCSIS), 8 - 11 September, 2013, Kraków, Poland, PTI, p. 105-110 (2013)

[42] Miller, M.: Cloud computing: web-based applications that change the way you work and collaborate online, IN: Que Publishing (2009)

[43] Nieger, D., Rotaru, K., \& Churilov, L.: Supply chain risk identification with value-focused process engineering, Journal of Operations Management, 27, p. 154-168, Elsevier (2009)

[44] Lee, D., Kwon, J., Lee, S., Park, S., \& Hong, B.: Scalable and efficient web services composition based on a relational database, The Journal of Systems and Software, 84: p. 2139- 2155, Elsevier (2011)

[45] Zhang, Q., Cheng, L. \& Boutaba, R.: Cloud computing: state-of-the-art and research challenges, Journal of Internet Services and Applications, 11 (1), p. 7-18 (2010)

[46] Zhang, J., Levy, D., Chen, S., \& Zic, J.: mBOSSS+: A Mobile Web Services Framework, IEEE Computer Society, p. 91-96, IEEE (2010)

[47] Wang, X.: Analysis on cloud computing-based logistics information network mode, IEEE Computer Society, IEEE, p. 1286-1289, IEEE (2011)

[48] Buyya, R., Ranjan, R., \& Calheiros, R. N.: InterCloud: Utility-Oriented Federation of Cloud Computing Environments for Scaling of Application Services, Hsu, C. H. et al. (Eds.), In ICA3PP 2010 - Part I, LNCS 6081, p. 13-31, Springer, Heidelberg (2010)

[49] Sakr, S.: Cloud-hosted databases: technologies, challenges and opportunities, Cluster Computing, Digital Objects Identifier: 10.1007/s10586-013-0290-7, p. 1-16, Springer, Heidelberg (2013)

[50] Grossniklaus, M.: The Case for Object Databases in Cloud Data Management, In ICOODB 2010, LNCS 6348, p. 25-39, Springer-Verlag Berlin Heidelberg (2010)

[51] Svensson, T. \& Popescu, A.: Development of laboratory exercises based on OPNET Modeler, Published Master Thesis, Blekinge Institute of Technology, Sweden, p. 2-268 (2003)

[52] Dunaytsev, R.: Network Simulators: OPNET Overview and Examples, Department of Communications Engineering, Tampere University of Technology, p. 1-69 (2010) 